\title{
R\&D, Learning by Doing and Economic Growth
}

\author{
Andrianasy A. Djistera \\ Université de Toamasina
}

This paper examines the relation between technical progress and economic growth. We build a growth model where the technological change depends on investment in research and development. Growth is determined by the imitation in the first stage of development, then innovation takes place. Assimilation and adaptation of technology produced in more advanced country play a crucial role in technological catch-up, but this imitation requires a precondition, an investment in human capital. The later remains a crucial factor of growth after the catch-up. Government can favour the economic growth facilitating and stimulating the technological change.

Keywords: economic growth, human capital, imitation, innovation, research and development, technological change

\section{INTRODUCTION}

The creation and the use of knowledge play an important role in the modern industrial economies. All productive activities require some kinds of knowledge. Arrow (1962) showed that technological change implies a modification of production function. He also highlighted that technological progress requires some effort and it is the product of experience acquired during activity. Taking into account this idea, Romer (1986) proposed a model of growth where the learning by doing allows a continuous rise in the production. This process can change the technical state but there is a body of literature (Kuznets, 1966; Rosenberg, 1982) considering that investment in research and development (R\&D) produces available knowledge in the economy. The New growth theory also considers that this investment is a crucial factor of economic growth. Most of endogenous growth models show that growth rate increases with the number of researchers allocated to R\&D activities (Romer, 1990; Grossman \& Helpman, 1990; Aghion \& Howitt, 1992).

The positive impact of activities related to $R \& D$ and innovation on economic growth in the case of industrialised countries (having especially an important endowment of human capital) is sufficiently studied. The relation is less obvious in the case of less developed countries. However, technology evolves rapidly in many emerging countries and most of them (South Korea, Singapore, etc.) are in competition with industrialised countries in terms of technology. The changes in the technical state also explains the "Asia's Miracle", and human capital endowment makes it possible. However, technological catch-up is less rapid in economies such as Indonesia and Philippines where there are less skilled workforce and that have often more natural resources.

The object of this paper is to consider in theoretical terms the effect of the relation between skilled workforce and technological change on economic growth. We propose a growth model based on Romer 
(1990) in order to improve our general understanding of the relation between technical progress and growth. The change of technology in our model takes into account imitation and innovation. These two processes require investment in $\mathrm{R} \& \mathrm{D}$ and skilled workforce.

The paper is organised as follows. In section 2, we describe the general framework of the model. Section 3 examines the growth in the long run. Some policy implications of the model are presented in section 4 . The last section concludes.

\section{DESCRIPTION OF THE MODEL}

The foundation of our model is the well-known model of Romer (1990). Following, Pissarides (1997), we differentiate the domestic and foreign produced technological knowledge. The economy has three sectors. The sector of final good which is perfectly competitive and produces a single homogenous consumption good. The intermediate goods sector which is monopolistically competitive and supplies a variety of inputs to producers of final good. Finally, the R\&D sector which supplies the intermediate goods producer with different designs. We assume that the number $L_{t}$ of skilled labor distributed between production of final good and R\&D activities is fixed.

\section{Final Good Production}

The production of final good depends on the skilled labor and the capital goods. The technology for producing final good is represented by the following function:

$Y_{t}=L_{Y t}^{\alpha} \int_{0}^{A_{t}} x(i)^{1-\alpha} d i, 0<\alpha<1$

where $Y_{t}$ is the output, $L_{Y t}$ is the skilled labour devoted to the production of final goods. $x(i)$ is the amount of intermediate good $i$ used in output production. $A_{t}$ is the domestic technology index denoting the number of intermediate goods available at time $t$. It constitutes the measure of technical change in this model. The parameter $\alpha$ is the share of intermediate good $x(i)$ in output. This specification follows DixitStiglitz (1977) and Ethier (1982).

Assuming that we use the same quantity of each intermediate good $(x(i)=x)$, the production function becomes:

$Y_{t}=L_{Y t}^{\alpha} A_{t} x^{1-\alpha}$

Perfect competition in this sector ensures that the marginal revenue and the marginal cost are equated. Notice that the demand of capital good $i$ is given by the equality between the price and the productivity marginal:

$p(x(i))=(1-\alpha) L_{Y t}{ }^{\alpha} x(i)^{-\alpha}$

\section{Intermediate Goods Production}

The producer of variety $i$ is in monopolistic competition and lends its output with the price $p(x(i))$ (that is equal to the productivity marginal of intermediate good) to final goods producers. The present value of the future operating profits of this producer is given by:

$R(x(i))=\int_{0}^{+\infty} e^{-r t} p(x(i)) x(i) d t$

where $r$ denotes the discount rate.

We assume that the cost to create a new type of intermediate goods is $\eta$ units of final goods. In addition, the production of each type of intermediate goods requires the purchase of a patent. Hence, the 
cost of production of intermediate goods at time $t$ has two components, on the one hand the cost of inputs measured in term of units of final goods $\eta x(i)$, and on the other hand the fixed-cost of patent $p_{A}$ paid to the inventor of variety $i$. The present value of the profit flow is:

$\pi^{a}=\int_{0}^{+\infty} e^{-r t} p(x(i)) x(i) d t-\eta x(i)-p_{A}$

As the present value of intermediate goods can be written $p(x(i)) / r$, we obtain:

$\pi^{a}=\frac{p(x(i)) x(i)}{r}-\eta x(i)-p_{A}$

Producer of intermediate goods maximises its profit by taking into account the produced quantity $x$. We obtain the marginal return $\left(R_{m}\right)$ by deriving the updated rent:

$R_{m}=\frac{(1-\alpha)^{2} L_{Y t}{ }^{\alpha} x^{-\alpha}}{r}$

and the marginal cost $\left(C_{m}\right)$ is:

$C_{m}=\eta$

In equilibrium, demand of intermediate goods is given by equality between equations (7) and (8):

$x^{*}=\left[\frac{\eta r}{(1-\alpha)^{2} L_{Y t}{ }^{\alpha}}\right]^{-1 / \alpha}$

Combining this equation with (3), we obtain the equilibrium value of the final good's price:

$p\left(x^{*}\right)=\frac{\eta r}{1-\alpha}$

\section{R\&D Activity}

In this benchmark model, technological change results from activities using skilled labor as an input and lead to new discoveries. It is especially based on imitation when the gap with technological frontier is higher. In this case, domestic firms assimilate and try to improve foreign technology. The imitation of the latter also is the main source of economic take-off in developing countries. Then, in the first stage of development, the evolution of technology is especially determined by imitation. Importing and adapting more advanced technology produced in foreign countries, domestic firms develop new products/processes. Imitation and technology absorption constitute a crucial factor for technological catch-up. Notice that R\&D activity is characterised by problem solving and innovation through trial-anderror process. Thus, the evolution of technology is influenced by learning by doing in R\&D sector. In the case of developing countries, technological change particularly on learning from foreign technology thought imitation (Pack, 1992; Tan \& Batra, 1995; Pissarides, 1997). This imitation notably is cheaper for developing countries firms than to attempt to make new discoveries.

The technological improvements depend on the skilled labor $L_{A t}$ working in R\&D activity, on the productivity of this sector captured by the parameter $\delta_{A}$, on the technological delay and on the aggregate stock $S(\quad$ ) of knowledge constituting an positive externality on the efficiency of research process. The later gathers the technology developed in the country and externalities associated to investment in research activity. Indeed, the development of new technologies requires the resolution of several problems generating trial-and-error and a portion of scientists and engineers (see Bessen, 1998). Innovation is associated to important learning-by-doing process. $\bar{A}_{t}$ denotes the externalities associated to this learning process. 
The evolution of technology is given by:

$\dot{A}_{t}=\delta_{A}\left(A_{t}^{e} / A_{t}\right) S\left(A_{t}, \bar{A}_{t}\right) L_{A t}$

This specification follows Romer (1990) and Pissarides (1997). The ratio $A_{t}^{e} / A_{t}$ represents the measure of technological gap in our model.

Assuming that $S\left(A_{t}, \bar{A}_{t}\right)=A_{t}{ }^{\beta} \bar{A}_{t}{ }^{\gamma}$, we get:

$\dot{A}_{t}=\delta_{A}\left(A_{t}^{e} / A_{t}\right) A_{t}^{\beta} \bar{A}_{t}^{\gamma} L_{A t}$

where the parameters $\beta$ and $\gamma$ denotes intensities of externalities of in R\&D activity.

Equation (12) captures two types of externalities in R\&D activity. The first is highlighted in most of $R \& D$ based model: the larger is the stock of knowledge, the higher is the productivity of skilled labor working in $\mathrm{R} \& \mathrm{D}$ sector. The second is associated to learning-by-doing process. In order to simplify the resolution of the model, we assume that $\gamma=1-\beta$. As $\bar{A}_{t}=A_{t}$, we have:

$\dot{A}_{t}=\delta_{A} A_{t}^{e} L_{A t}$

R\&D firms capture the income associated to the income associated with the patents acquired by the intermediate goods producers and assuming that researchers are the only inputs in $\mathrm{R} \& \mathrm{D}$ sector, the aggregate profit can be expressed as:

$\Pi_{A t}=p_{A}\left(\delta_{A} A_{t}^{e} L_{A t}\right)-w_{A} L_{A t}$

The market for design is perfectly competitive. Profit maximisation gives the return to labor devoted to research activity $^{1}$ ):

$w_{A}^{*}=p_{A} \delta_{A} A_{t}^{e}$

Assuming that R\&D firms are in a monopoly situation and that the price $p_{A}$ of patent allows capturing the actualised profits of capital goods producers buying patent, $p_{A}$ is given by:

$\pi^{a}=\frac{p(x(i)) x(i)}{r}-\eta x(i)-p_{A}=0$

Using equations (10) and (16), the equilibrium value of $p_{A}$ is:

$p_{A}^{*}=\frac{\alpha p\left(x^{*}\right) x^{*}}{r}=\frac{\alpha \eta x^{*}}{1-\alpha}$

According to equation (17), the higher is the interest rate, the lower is the discounted monopoly profit, and the price $p_{A}$.

\section{ANALYSIS OF GROWTH}

\section{Growth in Decentralised Equilibrium}

For a given value of $L_{A t}$, the growth rate for the technology $A_{t}$ is $\delta_{A}\left(A_{t}^{e} / A_{t}\right) L_{A t}$. From equation (2) the output $Y_{t}$ must grow at the same rate as $A_{t}$ if $L_{Y t}$ and $x$ are fixed. Since the total usage of capital $K_{t}$ is $A_{t} x \eta$, the capital stock must increase at the same rate as $A_{t}$.

In the present model, output can be either consumed or saved as new capital. The aggregate stock of physical capital evolves according to: 
$\dot{K}_{t}=Y_{t}-C_{t}$

where $C_{t}$ represents the aggregate consumption.

Since the ratio $K_{t} / Y_{t}$ is constant, equation (18) implies that $C_{t} / Y_{t}$ also is constant. Then $C_{t}, K_{t}, Y_{t}$ and $A_{t}$ increase with the same growth rate given by:

$g=\dot{Y}_{t} / Y_{t}=\dot{K}_{t} / K_{t}=\dot{C}_{t} / C_{t}=\dot{A}_{t} / A_{t}=\delta_{A}\left(A_{t}^{e} / A_{t}\right) L_{A t}$

Notice that the ratio $A_{t}^{e} / A_{t}$ is assumed to be constant in order to obtain a constant growth rate in the long run. Thus, growth rate in emerging country is higher during the stage of transition but growth rate are equated in steady state.

According to the equation (19), the growth rate depends on the number of researchers devoted to $\mathrm{R} \& \mathrm{D}$, the efficiency of this sector and the gap with technological frontier.

We show that the higher is the portion of skilled labor devoted employed in the R\&D sector; the higher is the higher is the growth rate. In order to determine $L_{A t}$ at decentralised equilibrium, we use the equilibrium condition of human capital allocation between research and final output sectors that the wage paid to labor in each sector must be the same (see Romer, 1990).

The total wage in research sector is $p_{A}\left(\delta_{A} A_{t}^{e} L_{A t}\right)$. Then, the return is:

$P m L_{A t}=p_{A} \delta_{A} A_{t}^{e}$

In final good sector, the return of labor is:

$P m L_{Y t}=\alpha L_{Y t}{ }^{\alpha-1} A_{t} x^{1-\alpha}$

To equalise returns to labor in both sectors, the price for new variety of intermediate goods at equilibrium must be choose so that

$p_{A}^{*} \delta_{A} A_{t}^{e}=\alpha L_{Y t}{ }^{\alpha-1} A_{t} x^{1-\alpha}$

When equations (9), (17) and (22) are combined, the labor working in research sector can then be written as:

$L_{A t}^{*}=L-\frac{r}{(1-\alpha) \delta_{A}\left(A_{t}^{e} / A_{t}\right)}$

From equations (18) and (23), we obtain the decentralised equilibrium growth rate:

$g^{*}=\dot{A_{t}} / A_{t}=\delta_{A}\left(A_{t}^{e} / A_{t}\right)\left[L-\frac{r}{(1-\alpha) \delta_{A}\left(A_{t}^{e} / A_{t}\right)}\right]$

Consumers have discounted and constant elasticity preferences in continuous time. The utility function is given by:

$U=\int_{0}^{+\infty} e^{-\rho t} u\left(C_{t}\right) d t \operatorname{avec} u\left(C_{t}\right)=\frac{C_{t}^{1-\sigma}-1}{1-\sigma}$

where $\rho$ is the rate of time preference and $\sigma$ is the inverse of the constant intertemporal elasticity of substitution.

The Ramsey-Keynes optimality condition gives the growth rate of aggregate consumption: 


$$
\dot{C}_{t} / C_{t}=(r-\rho) / \sigma
$$

where $r$ is the interest rate.

Equating equations (24) and (26), we get the equilibrium interest rate:

$r^{*}=\left[\sigma \delta_{A}\left(A_{t}^{e} / A_{t}\right) L\right] \frac{1-\alpha}{1-\alpha+\sigma}$

The amount of labor allocated in research is obtained substituting the interest rate in equation (23) by its equilibrium value:

$L_{A t}^{*}=\frac{(1-\alpha) \delta_{A}\left(A_{t}^{e} / A_{t}\right) L-\rho}{\delta_{A}\left(A_{t}^{e} / A_{t}\right)(1-\alpha+\sigma)}$

Then using equation (19) and (28), the decentralised equilibrium growth rate is:

$g^{*}=\frac{(1-\alpha) \delta_{A}\left(A_{t}^{e} / A_{t}\right) L-\rho}{1-\alpha+\sigma}$

Equation (29) presents the main determinants of growth. The larger is the technological delay captured by $A_{t}^{e} / A_{t}$, the higher is the growth rate. In this context, the technological catch-up phase explains the "growth miracle". Skilled labor resource abundance also determines the growth rate because both imitation and innovation require specific qualification.

This model permits to analyse the importance of skilled labor resource in economic take-off. Equating equation (29) to 0 , we get the minimum amount of skilled labor required for technical progress.

$L_{\min }=\frac{\rho}{(1-\alpha) \delta_{A}\left(A_{t}^{e} / A_{t}\right)}$

In this context, resources in skilled labor are too low and the economy devotes no labor in $R \& D$ activity allowing technological change. If $L_{\min }=L_{Y t}$, the economic growth cannot take place because $L_{A t}=0$

We show that the assimilation of the knowledge developed in more advanced economies allows the "economic take-off" of developing countries where there is a lack of skilled labor for original discovery. In this case, $A_{t}^{e}$ is higher than $A_{t}$ and the growth is more rapid in less developed country. However, growth is driving by innovation in the long run where $A_{t}^{e}$ and $A_{t}$ are equated.

\section{Growth in Centralised Equilibrium}

In this model, the social planning problem can be written as:

$$
\begin{gathered}
\quad \operatorname{Max} \int_{0}^{+\infty} e^{-\rho t} \frac{C_{t}^{1-\sigma}-1}{1-\sigma} \mathrm{dt} \\
\text { s.t. } \dot{A}_{t}=\delta_{A} A_{t}^{e} L_{A t} \\
\dot{K}_{t}=\left(L-L_{A t}\right)^{\alpha} A_{t}^{\propto} K_{t}^{1-\alpha} \eta^{\alpha-1}-C_{t}
\end{gathered}
$$

The updated value of the Hamiltonian associated to the social optimisation problem is expressed by:

$$
H=e^{-\rho t} \frac{C_{t}{ }^{1-\sigma}-1}{1-\sigma}+\lambda_{1 t} e^{-\rho t}\left\{\left(L-L_{A t}\right)^{\alpha} A_{t}{ }^{\alpha} K_{t}{ }^{1-\alpha} \eta^{\alpha-1}-C_{t}\right\}+\lambda_{2 t} e^{-\rho t}\left\{\delta_{A} A_{t}^{e} L_{A t}\right\}
$$

where $\lambda_{1 t}$ and $\lambda_{2 t}$ are multipliers.

The necessary conditions follow by maximising $H$ are given by: 
$\frac{\partial H}{\partial C_{t}}=0, \frac{\partial H}{\partial L_{A t}}=0, \dot{\lambda}_{1 t}=\rho-\frac{\partial H}{\partial A_{t}}, \dot{\lambda}_{2 \mathrm{t}}=\rho-\frac{\partial H}{\partial \mathrm{K}_{\mathrm{t}}}$

We have the following relations:

$\frac{\dot{\lambda}_{1 t}}{\lambda_{1 t}}=-\rho \frac{\dot{C}_{t}}{C_{t}}$

$\frac{\lambda_{1 t}}{\lambda_{2 t}}=\frac{\delta_{A} A_{t}^{e}}{\alpha\left(L-L_{A t}\right)^{\alpha-1} A_{t}^{\alpha} K_{t}^{1-\alpha} \eta^{\alpha-1}}$

$\frac{\dot{\lambda}_{2 t}}{\lambda_{2 t}}=\rho-\frac{\lambda_{1 t}}{\lambda_{2 t}} \alpha\left(L-L_{A t}\right)^{\alpha} A_{t}^{\alpha-1} K_{t}^{1-\alpha} \eta^{\alpha-1}$

$\frac{\dot{\lambda}_{1 t}}{\lambda_{1 t}}=\rho-(1-\alpha)\left(L-L_{A t}\right)^{\alpha} A_{t}^{\alpha} K_{t}{ }^{-\alpha} \eta^{\alpha-1}$

When equations (32) and (33) are combined, we get:

$\frac{\dot{\lambda}_{2 t}}{\lambda_{2 t}}=\rho-\delta_{A} \frac{A_{t}^{e}}{A_{t}}\left(L-L_{A t}\right)$

Equation (32) leads to the following relation:

$\frac{\dot{\lambda}_{2 t}}{\lambda_{2 t}}=\frac{\dot{\lambda}_{1 t}}{\lambda_{1 t}}+\frac{\dot{A}_{t}}{A_{t}}$

Combining equations (31), (35) and (36), the amount of labour allocated in R\&D activities can be expressed as:

$L_{A t}^{* *}=\frac{\delta_{A}\left(A_{t}^{e} / A_{t}\right) L-\rho}{\delta_{A}\left(A_{t}^{e} / A_{t}\right) \sigma}$

Hence, the growth rate in centralised equilibrium is:

$g^{* *}=\frac{\delta_{A}\left(A_{t}^{e} / A_{t}\right) L-\rho}{\sigma}$

Comparing equations (29) and (38), we show that the social optimal growth rate is greater than the growth rate in decentralised equilibrium. The difference can be explained by the fact that taking into account the externalities in research sector, social planner allocated more skilled labor in this activity. These results encourage public intervention in $R \& D$.

\section{POLICY IMPLICATIONS}

Long-run growth is based on technical progress depending especially on R\&D activity. Government can favour technical improvements through many measures (investment in $R \& D$, incentives human capital development or patent laws).

\section{Importance of Public R\&D Financing}

Investment in $R \& D$ allows sustaining economic growth through technical progress. Government can play crucial role through financing public $R \& D$ or favoring private $R \& D$. We examine the significance of public R\&D in Asian emerging countries. 
Evidence shows that governments play an important role in $R \& D$ activities by financing a great part of R\&D investments. For example, between 1996 and 2017, its contribution in gross domestic expenditure on R\&D (GERD) is higher than 1/3 in emerging Asian economies. However, there are important differences in the amplitude of contribution. According to Table 1, it is higher than $2 / 3$ in Hong Kong whereas it is lower than 1/3 in Korea from 1996 to 2017.

\section{TABLE 1}

GERD BY SOURCE OF FUNDS (\%) (AVERAGE 1996-2017)

\begin{tabular}{|c|c|c|c|c|c|}
\hline Economies & $\begin{array}{c}\text { Business } \\
\text { enterprise }\end{array}$ & Government & $\begin{array}{c}\text { Higher } \\
\text { education }\end{array}$ & $\begin{array}{c}\text { Private } \\
\text { non-profit }\end{array}$ & Abroad \\
\hline China & 70,6 & 23,9 & - & - & 1,2 \\
\hline Hong Kong & 45,2 & 50,5 & 0,1 & - & 4,2 \\
\hline Korea, Republic of & 73,5 & 24,0 & 1,5 & - & 0,4 \\
\hline Malaysia & 57,6 & 27,5 & 4,9 & - & 2,0 \\
\hline Philippines & 58,1 & 29,6 & 6,7 & 0,4 & 4,4 \\
\hline Singapore & 55,0 & 38,8 & 1,1 & - & 5,2 \\
\hline Thailand & 42,4 & 35,5 & 13,7 & 1,3 & 2,4 \\
\hline Average & 57,5 & 32,8 & 4,7 & 0,9 & 2,8 \\
\hline
\end{tabular}

Source: UNESCO Institute for Statistics, author calculations

\section{Education Policy}

We presented a general model analysing the implication of relation between the technical progress and the skilled labor resource on the long-run growth of economy. It gives interesting economic policy lessons for countries of a level of development considered. Contributing to technical progress, imitation plays crucial role in "growth miracle" or "economic take-off" but the technological innovation is the main determinant of long-run growth. Allowing technical improvements, imitation plays crucial role in Asian "growth miracle", but innovation determines the technological change in the long-run. Education policy plays important role favoring skilled labor supply. However, government must favor trade and FDI that are important vectors of technology transfers (Artus, 2005).

Notice that government must favor activities that aim to innovate because they allow sustaining longrun growth. Indeed, after the technological catch-up, countries must strengthen innovation in order to maintain a continuous growth of output. The evolution of the total R\&D personnel per million inhabitants shows the determination of these economies to pass from the imitation to innovation. Near to $10 \%$ of the number of researchers available in advanced countries in 1980, it represents a value higher than $50 \%$ in 2017. However, there appear important differences with respect to $R \& D$ personnel. The Asian catch-up is especially explained by the good performance of Korea and Singapore, whereas the indicator is very low in other Asian countries.

In the case of emerging Asian economies, evidence shows that they develop progressively knowledge intensive activities. We can illustrate it by the South Korean experience. Korean firms have progressively built their industrial capacity through imitation and learning since 1960s (Kim, 1997). They also have acquired and improved imported technology in order to adapt it to local market needs and to improve their technological capacity. Moreover, they have intensified their investment in R\&D during 1990s in order to pass from imitation to innovation.

More recently, China also tends gradually to move from imitation to innovation. For example, this country has developed its own technological standards. The Chinese consortium E-World Digital Technology (collaborating with United States firms On2 Technologies) launched in 2003 the compression audio/video codecs. The use of On2 Technology's VP5 and VP6 data compression technology as a substitution of MPEG-2 allows saving royalties ${ }^{2}$. 
TABLE 2

R\&D PERSONNELS PER MILLION INHABITANTS

\begin{tabular}{|c|c|c|c|c|c|c|c|c|c|c|}
\hline Economies & 1980 & 1985 & 1990 & 1995 & 2000 & 2005 & 2010 & 2015 & 2016 & 2017 \\
\hline China & - & - & - & 347 & 719 & 1033 & 1878 & 2691 & 2763 & 2862 \\
\hline $\begin{array}{c}\text { Korea, } \\
\text { Republic of }\end{array}$ & 484 & 1017 & 1645 & 2235 & 2914 & 4421 & 6765 & 8737 & 8809 & 9242 \\
\hline India & 131 & 134 & 151 & 157 & 302 & 342 & 358 & - & - & - \\
\hline Indonesia & 110 & 127 & 182 & - & 266 & - & - & - & 228 & 245 \\
\hline Malaysia & - & - & 88 & 93 & 434 & - & 1796 & 2681 & 2859 & - \\
\hline Singapore & 485 & 908 & 1426 & 2318 & 4948 & 6365 & 7294 & - & - & - \\
\hline Thailand & - & - & 87 & 118 & - & 565 & - & 1305 & 1632 & - \\
\hline $\begin{array}{c}\text { Emerging } \\
\text { Asia }\end{array}$ & 303 & 547 & 597 & 878 & 1597 & 2545 & 3618 & 3853 & 3258 & 4116 \\
\hline United-States & 2859 & 3512 & 3675 & 3863 & 4537 & - & - & - & - & - \\
\hline France & 1391 & 1855 & 2186 & 2607 & 5494 & 5711 & 6311 & 6650 & - & 6689 \\
\hline Germany & - & - & - & & 5949 & 5819 & 6783 & 7839 & 8031 & 8300 \\
\hline Japan & 3778 & 4538 & 5395 & 5368 & 7032 & 6988 & 6829 & 6837 & 6829 & 6987 \\
\hline $\begin{array}{l}\text { Industrial } \\
\text { countries }\end{array}$ & 2676 & 3302 & 3752 & 3946 & 5753 & 6173 & 6641 & 7109 & 7430 & 7326 \\
\hline
\end{tabular}

Source: UNESCO Institute for Statistics, author calculations

\section{Effects of Intellectual Property Right}

The abundance of skilled labor is the main determinant of technological progress in most countries. Since education policy affect supply of skilled labor, it plays crucial role. However, the choice of IPR application decision also is important. Barton (2002) noted that countries use property right regime in order to realise their own economic interests. Then, several countries change their IPR regime throughout the development stage according to their idea on the subject (and their economic situation). Indeed, one cannot accept the presence of monopole in a crucial sector, and the gains associated to the measures favouring the free access to foreign technology are higher than the gains of national innovation incentives. This approach is notably adopted in emerging Asian economies (Korea, Taiwan) favouring domestic invention made in imitation and diffusion of foreign technology. They used weak property right protection according to their situation and development stage. During their rapid growth from 1960 to 1980, Korea and Taiwan developed their national innovation system using imitation and inverse engineering. For example, Korea established its first formal patent system in 1961 but it did not concern chemical and pharmaceutical products. Moreover, the protection duration was only 12 years. Patent laws reform appeared only in middle 1980s, under pressure of the United States using the Section 301 of the Trade Act. However, the standards defined in the Agreement on Traded-Related Aspect of Intellectual Property Rights (TRIPS) of World Trade Organization (WTO) are not yet respected. The evolution of the regulation on patents in South Korea is an illustration of the importance that public policy may have on technical progress.

In India, government also used IPR through its technological learning and the patent system has suffered several modifications that have strengthened or relaxed patent rights. The case of pharmaceutical industry is often highlighted (Latrive, 2004). Before the 1970s, domestic production was weak and the price of drugs was high because of price policy of foreign firms. This situation also is explained by the Indian Patents and Designs Act of 1911 made available product patents and composition of matter patents providing strong protection for drugs. Since the 1970s the country decides to solve the problem through the reform of the patent system (in order to ensure that the patent system does not hinder but promotes the availability of medicines at affordable prices for the national public health needs). Thus, the development of the national pharmaceutical industry in India is linked to the extent that national patent laws have 
allowed them to legally produce quality generic versions of many medicines even while these are under patent in other countries.

\section{CONCLUSION}

The paper develops a model of growth based on technological progress. The model assumes free flow of technology and two determinants of technical progress according to the development level. It depends on innovation in technologically leader countries, and on imitation in countries where there is a technological delay.

The long-run growth is explained by investment in $R \& D$ where human capital endowment especially is the key resources. Our model also shows that technological catch-up requires a sufficiently qualified labor. Thus, human capital policy matters. Finally, governments must favor the creation and transmission of knowledge.

\section{ENDNOTES}

1. Wage is equal to marginal productivity especially in footloose industries.

2. MPEG-2 refers to a technology that deals with the transmission, storage and display of digitised moving images. It is used in the manufacture of DVDs.

\section{REFERENCES}

Aghion, P., \& Howitt P. (1992). A Model of Growth through Creative Destruction. Econometrica, 60(2), 323-351.

Arrow, K. J. (1962). The Economic Implication of Learning by doing. Review of Economic Studies, 29(3), 152-173.

Artus, P. (2005, July). Les effets des particularités de la situation de la Chine sur les conséquences de l'ouverture des échanges commerciaux entre la Chine et les pays avancés. Document de travail IXIS, 21.

Barton, J. (2002). Integrating Intellectual Property Rights and Development Policy. Commision on Intellectual Property Rights, Londres.

Bessen, J. (1998). Productivity Adjustments and Learning-by-Doing as Human Capital. Mimeo.

Dixit, A. K., \& Stiglitz J. E. (1977). Monopolistic Competition and Optimal Product Diversity. American Economic Review, 67, 297-308.

Grossman, G. M., \& Helpman, E. (1990). Comparative Advantage and Long-run Growth. American Economic Review, 80(4), 796-815.

Kim, L. (1997). Imitation to Innovation: The Dynamics of Korea's Technological Learning. Harvard Business School Press.

Kuznets, S. (1966). Modern Economic Growth. Yale University Press: New Haven.

Latrive, F. (2004). Du bon usage de la piraterie - Culture libre, sciences ouvertes. Éditions Exils.

Pack, H. (1992). New Perspectives on Industrial Growth in Taiwan. In G. Ranis (Ed.), Taiwan: From Developing to Mature Economy. Boulder, Colo.: Westview Press.

Pissarides, C. A. (1997). Learning by Trading and the Returns to Human Capital in Developing Countries. The World Bank Economic Review, 11(1), 17-32.

Romer, P. M. (1986). Increasing Returns and Long Run Growth. Journal of Political Economy, 94, 10021037.

Romer, P. M. (1990). Endogenous Technological Change. Journal of Political Economy, 98, 71-102. Rosenberg, N. (1982). Inside the Black Box: Technology and economics. Cambridge University Press. Tan, H., \& Batra, G. (1995). Technology and Firm Size-Wage Differentials in Colombia, Mexico, and Taiwan (China). The World Bank Economic Review, 11(1), 59-84. 